\title{
Author Correction: CCR5AS IncRNA variation differentially regulates CCR5, influencing HIV disease outcome
}

Smita Kulkarni (D), Alexandra Lied, Viraj Kulkarni, Marijana Rucevic, Maureen P. Martin, Victoria Walker-Sperling, Stephen K. Anderson, Rodger Ewy, Sukhvinder Singh, Hoang Nguyen, Paul J. McLaren (D), Mathias Viard, Vivek Naranbhai, Chengcheng Zou, Zhansong Lin, Hiroyuki Gatanaga, Shinichi Oka, Masafumi Takiguchi, Chloe L. Thio, Joseph Margolick, Gregory D. Kirk, James J. Goedert, W. Keith Hoots, Steven G. Deeks D, David W. Haas, Nelson Michael, Bruce Walker ID, Sylvie Le Gall, Fatema Z. Chowdhury, Xu G. Yu and Mary Carrington D

Correction to: Nature Immunology https://doi.org/10.1038/s41590-019-0406-1, published online 17 June 2019.

In the version of this article initially published, the right two labels along the horizontal axis of Fig. 8c (IntA and IntG) were in the incorrect order. The correct order is IntG (middle right) and IntA (far right). The error has been corrected in the HTML and PDF versions of the article.

\section{Author Correction: Glycerol phosphate shuttle enzyme GPD2 regulates macrophage inflammatory responses}

P. Kent Langston (D), Aya Nambu (D), Jonathan Jung (D), Munehiko Shibata, H. Ibrahim Aksoylar, Jiahui Lei, Peining Xu, Mary T. Doan, Helen Jiang, Michael R. MacArthur, Xia Gao (D), Yong Kong (D), Edward T. Chouchani, Jason W. Locasale (D), Nathaniel W. Snyder and Tiffany Horng (iD

Correction to: Nature Immunology https://doi.org/10.1038/s41590-019-0453-7, published online 5 August 2019.

In the version of this article initially published, the surname of the penultimate author ('Synder') was incorrect. The correct surname is 'Snyder'. The error has been corrected in the HTML and PDF versions of the article.

\section{Author Correction: PD-1 blockade in subprimed CD8 cells induces dysfunctional PD $-1+C D 38^{\text {hi }}$ cells and anti-PD-1 resistance}

Vivek Verma, Rajeev K Shrimali, Shamim Ahmad, Winjie Dai, Hua Wang, Sumin Lu, Rahul Nandre, Pankaj Gaur, Jose Lopez, Moshe Sade-Feldman, Keren Yizhak, Stacey L. Bjorgaard, Keith T. Flaherty (D), Jennifer A. Wargo (D), Genevieve M. Boland, Ryan J. Sullivan D, Gad Getz D , Scott A. Hammond, Ming Tan, Jingjing Qi, Phillip Wong, Taha Merghoub (D), Jedd Wolchok (D), Nir Hacohen D, John E. Janik, Mikayel Mkrtichyan, Seema Gupta and Samir N. Khleif D

Correction to: Nature Immunology https://doi.org/10.1038/s41590-019-0441-y, published online 29 July 2019.

In the version of this article initially published, the information for affiliation 11 was incomplete. The correct, full affiliation is as follows: The Loop Immuno-Oncology Laboratory, Lombardi Comprehensive Cancer Center, Georgetown University Medical Center, Washington, DC, USA. The error has been corrected in the HTML and PDF versions of the article. 